\title{
Neutron diffraction measurement of residual stresses in an ITER-like tungsten-monoblock type plasma-facing component
}

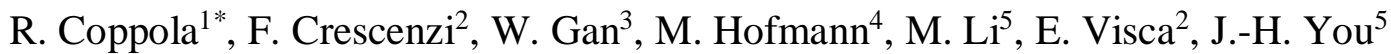

1. ENEA-Casaccia, FSN-SICNUC, Via Anguillarese 301, 00123 Roma, Italy

2. ENEA-Frascati, FSN-FUSTEC-TES, Via E. Fermi 45, 00044 Frascati (Roma), Italy

3. Heinz Maier-Leibnitz (FRM II) - Helmholtz Zentrum Geesthacht, Lichtenbergstr. 1, D-85748 Garching b. München, Germany

4. Heinz Maier-Leibnitz (FRM II) - Technische Universität München, Lichtenbergstr. 1, D-85748 Garching b. München, Germany

5. Max-Planck Institut for Plasma Phyisics, EUROfusion Consortium, Boltzmann Str. 2, D-85748 Garching b. München, Germany

* corresponding author: roberto.coppola@enea.it

Neutron diffraction measurements have been carried out for non-destructive characterization and numerical predictions validation of the residual stresses in a mock-up of the ITER-like divertor target plasma-facing component, made by hot radial pressing of 4 tungsten blocks to a $\mathrm{CuCrZr}$ cooling pipe via a soft copper interlayer. The neutron diffraction measurements were carried out, at room temperature, at FRM II reactor in Garching. Stress-relieved W and $\mathrm{CuCrZr}$ were examined as reference state before joining. The 3D stress tensor was determined in one of the two external $\mathrm{W}$-blocks and $\mathrm{CuCrZr}$ pipe segments, scanning the mock-up from the outer surface of the $\mathrm{W}$ block towards the inner wall of the $\mathrm{CuCrZr}$ pipe with the interval of $0.4-0.5 \mathrm{~mm}$. A residual stress distribution from tension to compression through the bonding line is detected, as expected from the requirement of force balance. Except at the interlayer, stresses well below $100 \mathrm{MPa}$ are found, confirming the good fabrication quality of the investigated monoblock. These experimental results are comparable with the FEM-based numerical prediction, but at the interlayer and inside the pipe a sharper spatial resolution is needed for the neutron diffraction measurements to catch the hoop and axial stress gradient profile.

Keywords: divertor, hot radial pressing, stress distributions, neutron diffraction, FEM

\section{Introduction}

A reliable and accurate characterization of residual stresses is of utmost relevance in the design of plasmafacing components and more specifically of the divertor [1]. Theoretical calculations and FEM modeling of the stress field present in such components provide an essential tool in the design phase, since they are based on well-assessed physical assumptions and mathematical procedures [2-4]. However, they need to be validated by comparison with experimental results, obtained by measuring the stresses, non-destructively and in the bulk, on the real components after all the fabrication steps are achieved. Neutron diffraction is probably the only technique capable of providing such experimental data; it is widely utilized for stress mapping in complex samples of industrial interest and it is based on an internationally acknowledged protocol, both concerning the measurements themselves and the data treatment. The comparison between such experimental results and the numerical predictions requires to analyze carefully the respective fundamental assumptions of the two procedures and to consider that ideal samples are usually assumed in modeling, while neutron diffraction experiments are carried out on real samples, potentially affected by undesired and uncontrolled uncertainties relating to sample fabrication, material heterogeneity, etc. This combined numerical and experimental procedure has been applied to the characterization of residual stresses in an ITER-like tungsten monoblock.

\section{Material characterization}

The investigated ITER-like diffusion bonded 4-tiles $\mathrm{W}-\mathrm{Cu}-\mathrm{CuCrZr}$ mock-up is shown in Fig. 1; reference is made to $[5,6]$ for a description of mock-up fabrication by hot radial pressing (HRP) at $580^{\circ} \mathrm{C}$ and all technical details. The bonding between the $\mathrm{W}$ tile and $\mathrm{CuCrZr}$ tube is obtained by a $0.1 \mathrm{~mm}$ thick pure $\mathrm{Cu}$ interlayer. The quality of the obtained bonding was tested by ultrasounds, finding good results for all of the four tiles, except within $1 \mathrm{~mm}$ from the outer surfaces of each tile. In addition to the mock-up, a stress relieved un-brazed tile and an un-brazed segment of $\mathrm{CuCrZr}$ tube were prepared as un-strained reference samples for the neutron diffraction measurements.

\section{Stress calculation}

For 3D FEM stress calculation, the same geometry, materials, temperature-dependent elastic/visco-plastic properties and fabrication process as the experimentally investigated mock-up were taken [7-11]. The heat treatment case B (solution-annealed and aged) of the ITER MPH was taken, as it turned out to be the closest to the actual tensile properties of the $\mathrm{CuCrZr}$ alloy pipe afterHRP. 

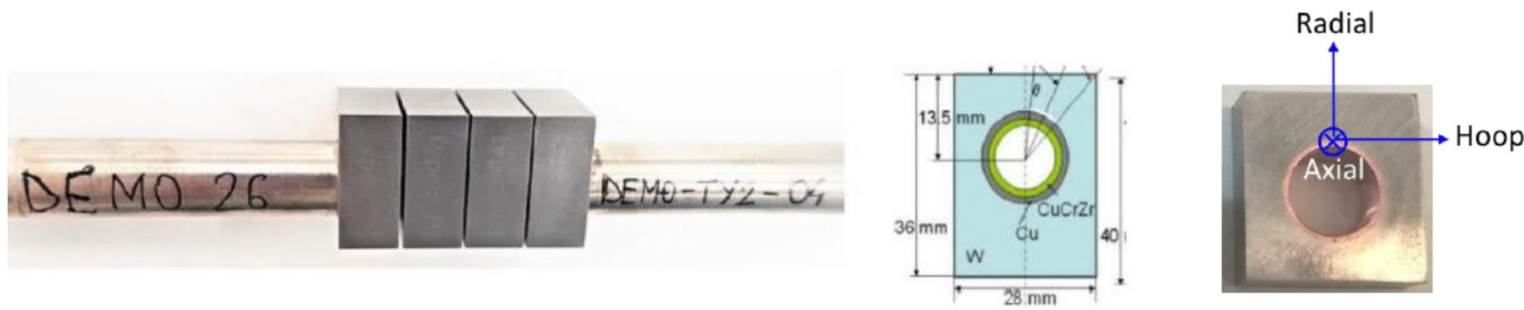

Fig. 1 - ITER-like diffusion bonded 4-tiles $\mathrm{W}-\mathrm{Cu}-\mathrm{CuCrZr}$ mock-up, with $0.1 \mathrm{~mm} \mathrm{Cu}$ interlayer, and related sizes; the W tiles are each $12 \mathrm{~mm}$ thick. The principal stress components are also indicated.

Stress-free temperature of $580^{\circ} \mathrm{C}$ and uniform cooling were assumed. The real time scale of HRP was taken together with the applied pressure for creep simulation, assuming only secondary creep due to the lack of material data. 3D quarter geometry model was used with kinematic symmetry boundary conditions. The thin $\mathrm{Cu}$ interlayer was included in the model [9]. $\mathbf{J}_{2}$ plasticity with the von-Mises type yield criterion was assumed, which allows at least one of the three principal stress components exceed the yield stress (see hoop stress in Fig. 4 below).

\section{Experimental technique}

Reference is made to [12-14] for a general presentation on the use of neutron diffraction for strain and stress determination and to [15-19] for applications to divertor components. The measurement of strains and stresses by neutron or X-ray diffraction is based on the well-known Bragg's law

$2 d_{h k l} \sin \theta=n \lambda$

relating the spacing, $d_{h k l}$ between crystallographic lattice planes characterized by Miller indices $h k l$ with the wavelength, $\lambda$, and the angle $2 \theta$ where the reflection is observed. The main advantage of utilizing neutron beams with respect to X-rays is their deeper penetration, up to a few $\mathrm{cm}$ in some materials. Defining the strain $\varepsilon$ as:

$\varepsilon=\frac{\left(d-d_{0}\right)}{d_{0}}$

where $d$ and $d_{0}$ are strained and un-strained lattice spacing respectively, $\varepsilon$ is determined by the shift in the position of the Bragg peaks. A 'strain-free' sample is therefore needed. Defining $X, Y, Z$ the principal directions of deformation, the residual stresses components are given by:

$$
\begin{aligned}
& \sigma_{X}=\frac{E}{(1+v)(1-2 v)}\left[(1-v) \varepsilon_{X}+v\left(\varepsilon_{Y}+\varepsilon_{Z}\right)\right] \\
& \sigma_{Y}=\frac{E}{(1+v)(1-2 v)}\left[(1-v) \varepsilon_{Y}+v\left(\varepsilon_{X}+\varepsilon_{Z}\right)\right] \\
& \sigma_{Z}=\frac{E}{(1+v)(1-2 v)}\left[(1-v) \varepsilon_{Z}+v\left(\varepsilon_{X}+\varepsilon_{Y}\right)\right]
\end{aligned}
$$

where $E$ is the Young modulus and $v$ the Poisson's ratio.
The neutron diffraction measurements were carried out, at room temperature, at the STRESS-SPEC diffractometer [20], operated at the FRM-II reactor, in Garching. The selected neutron wavelength was $1.47 \AA$, produced by a $\mathrm{Si}(004)$ monochromator. One of the two external $\mathrm{W}$-blocks and $\mathrm{CuCrZr}$ pipe segments were investigated, scanning the mock-up from the outer surface of the $\mathrm{W}$ block towards the inner wall of the $\mathrm{CuCrZr}$ pipe with the interval of $0.4-0.5 \mathrm{~mm}$. The measured gauge volumes, defined by primary slit and a radial collimator (FWHM $=1 \mathrm{~mm}$ ) at outgoing beam side, were the following: $1 \times 5 \times 1 \mathrm{~mm}^{3}$ for radial and hoop directions, $1 \times 3 \times 1 \mathrm{~mm}^{3}$ for $\mathrm{W}$ block and $1 \times 2 \times 1 \mathrm{~mm}^{3}$ for $\mathrm{CuCrZr}$ tube respectively in the axial direction. The 2D detector was set at $90^{\circ}$, to cover simultaneously W (310) reflection $\left(2 \theta \approx 94.4^{\circ}\right)$ and $\mathrm{Cu}(311)$ reflection $\left(2 \theta \approx 84.8^{\circ}\right)$, utilized to measure the peak shift and strain calculation. The experimental layout for the mock-up is shown in Fig.s 2 a-b, where the principal stress directions are indicated.

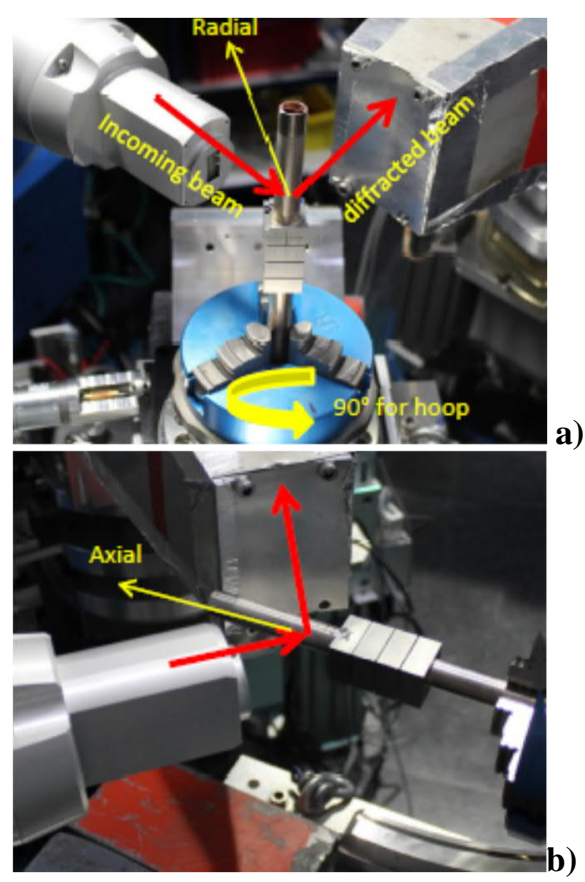

Fig. 2. Experimental layout for measurements of stress components in ITER-like diffusion bonded 4-tiles W-CuCrZr mock-up, with $0.1 \mathrm{~mm} \mathrm{Cu}$ interlayer: a) radial and hoop components, b) axial component. 
The SteCa fitting procedure [21] was utilized to fit the measured diffraction peaks and to obtain the $2 \theta$ value of each point, with associated errors. The correction of so called spurious strains [22], due to the instrument setup, has been applied to the points close to the interlayer. Strains were calculated by Eq. (1). Then, by Eq.(3), the stresses were calculated, assuming Young moduli and Poisson's ratio values of $401 \mathrm{GPa}$ and 0.283 for $\mathrm{W}$, and of $128 \mathrm{GPa}$ and 0.33 for $\mathrm{CuCrZr}$ respectively $[6,8]$.

\section{Results and discussion}

Fig. 3 and Fig. 4 present the three principal components of residual strains and stresses, respectively measured by neutron diffraction, each one compared to the numerically FEM calculated residual strains and stresses.

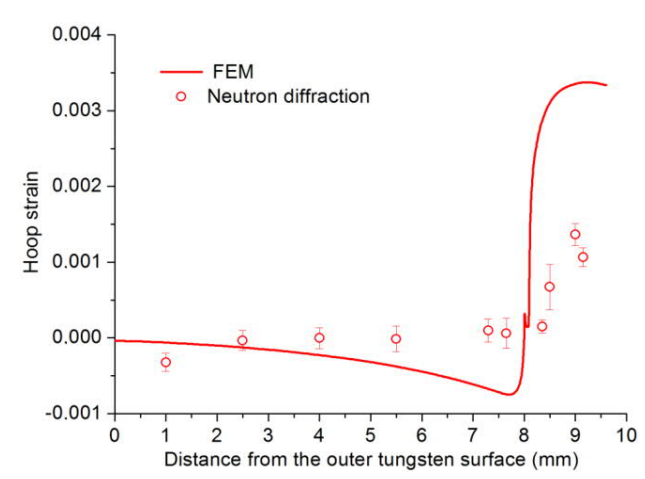

a)

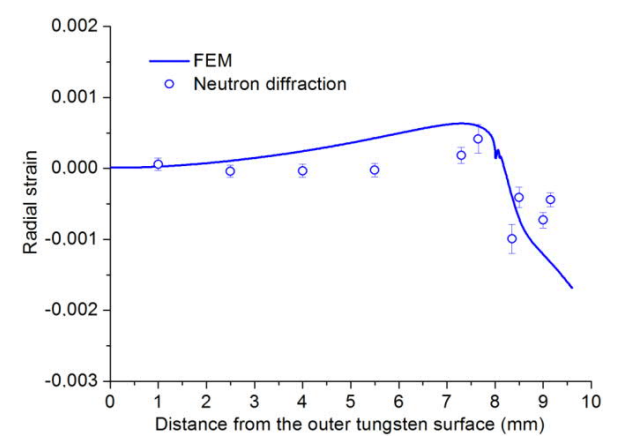

b)

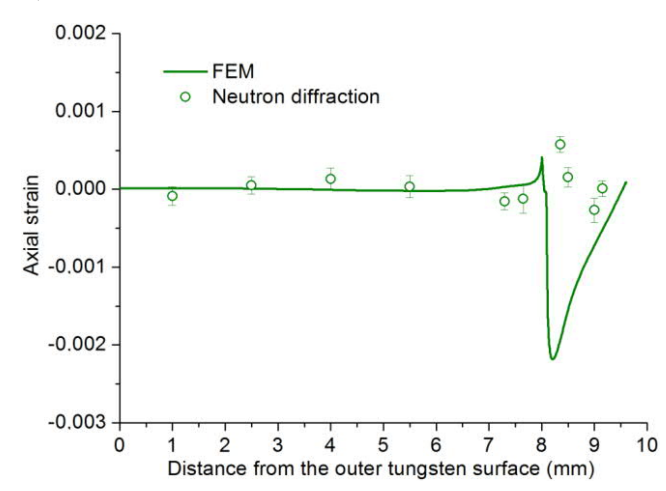

c)

Fig. 3. Experimentally measured and numerically calculated residual micro-strains for the three principal components illustrated in Fig. 2. The $\mathrm{Cu}$ interlayer is located at approximately $8 \mathrm{~mm}$.
Generally, the experimental data show a very low strain level for all three strain components through the vertical scan profile except in the cooling pipe region. In the tungsten armor region, no significant remnant strain is measured as predicted by FEM indicating that there is neither macroscopic residual stress due to differential thermal strain mismatch nor mesoscopic stress due to micro-structural heterogeneity or any other fabrication defect. The latter confirms the good fabrication quality of the sample mock-up used. On the other hand, a discrepancy is seen at the interlayer and inside the pipe for the hoop and the axial components. This is tentatively attributed to factors limiting the accuracy of either the experimental measurement or the numerical simulation, or probably both.

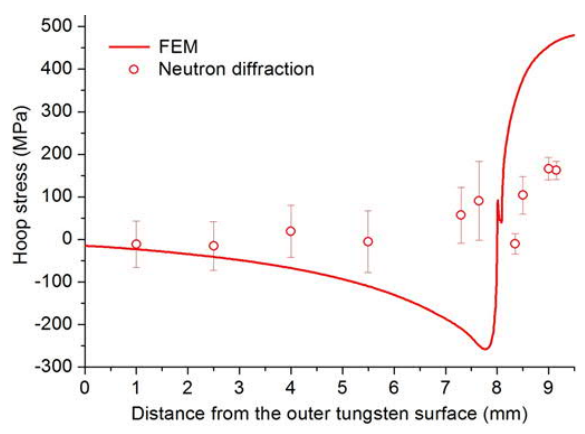

a)

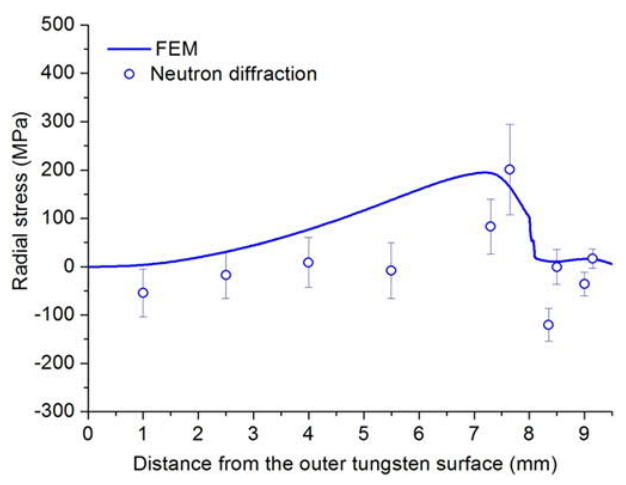

b)

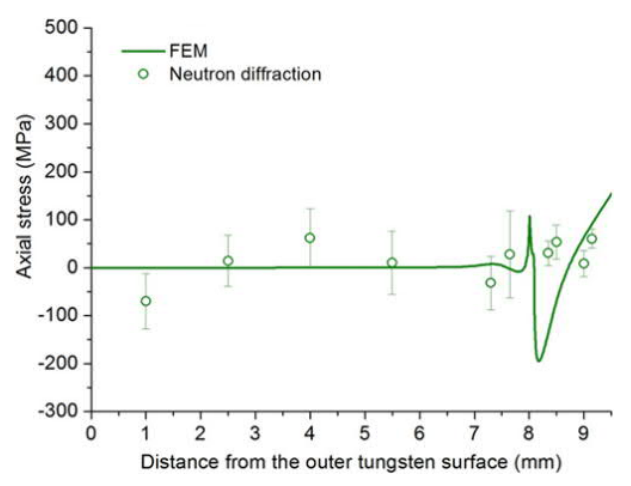

c)

Fig. 4. Experimentally measured and numerically calculated residual stresses for the three principal components illustrated in Fig. 2. The $\mathrm{Cu}$ interlayer is located at approximately $8 \mathrm{~mm}$. 
Namely, as already mentioned the spatial resolution of the neutron beam scan was relatively coarse $(0.4-0.5$ $\mathrm{mm})$ and the gauge volume was rather big as well $(2,3$ or $5 \mathrm{~mm}^{3}$, depending on the stress components) so that the obtained strain profile, particularly in the sharp transition region around the interlayer and inside the pipe, is averaged over a voxel volume far too large to accurately observe the involved deformation mechanisms. Furthermore, the crystallographic texture present in the extruded pipe complicates the diffraction measurements and is not included in the FEM model; $\mathrm{Cu} / \mathrm{CuCrZr}$ inter-diffusion should also be investigated, to check possible changes in the lattice spacing of the pipe. A sharper linear spatial resolution and gauge volume shall be adopted in the future measurements, possibly comparable with the size of the interlayer region $(0.1$ $\mathrm{mm}$ ) and more adequate for mapping the $2 \mathrm{~mm}$ thick $\mathrm{CuCrZr}$ pipe.

Another major source of errors may be attributed to the material model (particularly $\mathrm{CuCrZr}$ ) used for FEM. For the thermal strain simulation, a monotonic elastoviscoplastic constitutive model was employed where $\mathbf{J}_{2}$ type plasticity (i.e. von Mises yield criterion) with isotropic hardening and the secondary creep was considered using temperature dependent material parameters. However, the primary creep was not applied due to the complete lack of material data in the literature. The primary creep should have a much pronounced effect on stress relaxation than the secondary creep, especially for a short period thermal exposure. The numerical analysis revealed that the stress relaxation effect by the secondary creep was surprisingly negligible, though the duration of the joining process amounted to 5 hours at $500-600^{\circ} \mathrm{C}$. It is still an open question that to what extent the primary creep would relax the intensity of residual stresses. This issue remains a topic for future study.

\section{Conclusions}

Numerical modeling and experimental investigation, by means of neutron diffraction, have been combined to characterize the stress field in an as-received 4 tiles ITER-like divertor monoblock. Experimental strain and stress values are in the same order of magnitude as the theoretical ones and also in several of the investigated points coincident, within the experimental errors. A sharper gauge volume and additional micro-structural information on the $\mathrm{Cu} / \mathrm{CuCrZr}$ interface will be necessary to provide a more detailed mapping at the interlayer and inside the pipe, in order to validate the strain and stress gradients numerically predicted in such a critical region.

\section{Acknowledgments}

This work has been carried out within the frame of the EUROfusion Consortium and has received funding from the Euratom research and training programme 20142018 under grant agreement No 633053. The views and opinions expressed herein do not necessarily reflect those of the European Commission.

\section{References}

[1] M. Fursdon, J.H. You, T. Barrett, M. Li, Fus. Eng. \& Des. 135 (2018) 154-164.

[2] M. Fursdon, J.-H. You, T. Barrett, M. Li, Fus. Eng. \& Des. 124 (2017) 468-472.

[3] M. Li, E. Werner, J.H. You, Fus. Eng. Des. 90 (2015) 8896.

[4] M. Fursdon, M. Li, J.H. You, these Proceedings

[5] F. Crescenzi, E. Cacciotti, V. Cerri, H. Greuner, S. Roccella, E. Visca, J.H. You, Fus. Eng. Des. 136 (2018) 558-562.

[6] Visca, B. Böswirth, E. Cacciotti, V. Cerri, F. Crescenzi, F. Gallay, H. Greuner, Reale, M. Richou, S. Roccella, J.H. You, F. Maviglia, Fus. Eng. Des. https://doi.org/10.1016/j.fusengdes.2018.05.064

[7] M. Li, J.H. You, Nucl. Mater. Ener. 14 (2018) 1-7.

[8] ITER Document No. G74 M 16, ITER Material Properties Handbook, 2005.

[9] M. Li, F. Gallay, M. Richou, J.H. You, Fus. Eng. Des. 122 (2017) 124-130.

[10] M. Li, J.H You, EUROfusion Report Task WPDIV Report N: RT-WP-DIV-Phase2-ENEA-26_Rev0

[11] ITER Document No. S 74 MA 2 File Code: ITER-AK022111

[12] M. Hutchings, C. G. Windsor, in K. Sköld, in D. L. Price Ed.s Methods of Experimental Physics, vol 23-c, Neutron Scattering, Academic, 1987, p. $405-482$

[13] C. G. Windsor, in Industrial and Technological Applications of Neutrons, M. Fontana, F. Rustichelli and R. Coppola Ed.s, North Holland (1992), p. 167-200

[14] M.T. Hutchings, P.J. Withers, T.M. Holden, T. Lorentzen, Introduction to the Characterization of Residual Stress by Neutron Diffraction, Taylor \& Francis (2005)

[15] R. Coppola, C. Nardi, B. Riccardi, J. Nucl. Mat. 283287 (2000) 1243 - 1247

[16] R. Coppola, C. Nardi, T. Pirling, R. Wimpory, Appl. Phys. A 74 (2002) S1713-1715

[17] R. Coppola and C. Nardi, in Analysis of Residual Stress by Diffraction using Neutron and Synchrotron Radiation, M. E. Fitzpatrick and A. Lodini Ed.s, Taylor \& Francis (2003) pp 319-333

[18] C. Braham, R. Coppola, C. Nardi, M. Valli, Fus. Eng. \& Des. 75-79 (2005) 391 -394

[19] R. Coppola, C. Ohms, J. Reiser, M. Rieth, R. C. Wimpory, Nucl. Mat. En. 3-4 (2015) 37-42

[20] http://www.mlz-garching.de/instrumente-undlabore/struktur/stress-spec.html and https://jlsrf.org/index.php/lsf/article/view/25

[21] http://apps.jens.fzjuelich.de/doku/sc/steca2:typical_workflow

[22] J. R. Kornmeier, J. Šaroun, J. Gibmeier, M. Hofmann, Mat. Sci. Forum 768769 (2014) 52-59 